\title{
ANÁLISIS INTRADISCURSIVO DE DUEL, DE STEVEN SPIELBERG
}

\author{
Santiago GARCÍA OCHOA \\ Universidad de Santiago de Compostela \\ santiago.ochoa@terra.es
}

Resumen: Cada película funciona como una encrucijada de discursos culturales procedentes de la sociedad, el arte, el cine, la literatura, etc. Duel (El diablo sobre ruedas, 1972) resulta un ejemplo singularmente representativo de este fenómeno.

Abstract: Each film functions like an intersection of cultural discourses coming from society, arts, cinema, literature, etcetera. This phenomenon is particularly perceptible in a movie like Duel (1972).

Palabras clave: Cine. Duel. Intradiscursividad.

Keywords: Cinema. Duel. Intradiscursivity. 


\section{UNA ÓPERA PRIMA SINGULAR}

Tras la realización de diversos episodios de series televisivas para la Universal, Steven Spielberg dirige Duel, su primera película para la televisión. Basada en una historia original de Richard Matheson, convertida en guión por el propio autor ${ }^{1}$, se estrenó el 13 de noviembre de 1971, en el espacio «La película de la semana» de la cadena ABC. El éxito de crítica y público llevó a los directivos de la Universal a decidir su estreno en los cines de Eu$\mathrm{ropa}^{2}$. Por este motivo se añadieron a la película varias escenas adicionales, pasando su metraje de 74 minutos hasta casi los 90 , y se cambió su formato televisivo por otro más cinematográfico $(1,85: 1)$, con el consiguiente aumento de grano y pérdida de calidad. La película se presentó en Cannes en mayo de 1972 y se estrenó en Londres en octubre, pero en una sola sala, fuera del West End, con la pretensión de que permaneciera como mucho dos semanas en cartelera. Su verdadero estreno comercial europeo tuvo lugar en $1973^{3}$. En este año obtuvo diversos galardones como colofón al éxito de crítica que ya había cosechado: Gran Premio del Festival de Avoriaz (Francia), Garridi d'Oro a la mejor ópera prima en el Festival de Taormina (Italia), Mención especial en el Festival de Televisión de Montecarlo (Mónaco). Spielberg había alcanzado la fama. El éxito obtenido en Europa y la enorme popularidad del director, impulsaría a los estudios Universal a estrenar Duel en los cines de Estados Unidos, en el año 1983, aunque los resultados no fueron los esperados.

\section{PROPUESTA METODOLÓGICA}

Cualquier película es una encrucijada de discursos culturales. González Requena lo ha expuesto de manera coherente:

\footnotetext{
${ }^{1}$ En parte debido a unas declaraciones de Spielberg, tradicionalmente se había considerado el relato de Matheson publicado en Play Boy (abril, 1971) como el punto de partida de la película. Según Baxter, sin embargo, Matheson ya tenía escrito el guión y lo había dado a conocer a diversas productoras, por lo que realmente ocurrió fue que «un amigo en el departamento de correo interno, otra pieza de su [de Spielberg] cuidada relación de contactos, le pasó un guión interesante...» (Baxter, 1998: 74).

${ }^{2}$ Amblin (1967), el corto de Spielberg que había propiciado su contrato en la división televisiva de la Universal, ya había sido premiado en el segundo Festival de Cine de Atlanta en 1969 y al año siguiente se había estrenado en salas, antecediendo a la película de Arthur Hiller, Love Story. Duel obtuvo en 1971 el Emmy a la mejor fotografía.

${ }^{3}$ En España Duel se estrenó con el título de El diablo sobre ruedas, el 5 de noviembre de 1973 (Madrid).
} 
El film - cada film — es un espacio donde los lenguajes trabajan y este trabajo - la escritura - es huella de mil conexiones y del mil violencias con respecto a un intertexto definido por la totalidad de los universos culturales que lo arropan (González Requena, 1988: 19).

Partiendo de esta postura crítica frente a la semiótica queremos establecer un ámbito metodológico más preciso. La palabra intertextualidad contiene texto, y por lo tanto debe emplearse sólo para designar las relaciones entre texto y texto (ya sea escrito, artístico, audiovisual, etc.). Una denominación más concreta para enfrentarse a todos los discursos culturales registrados en un texto es la de interdiscursividad (Marchese y Forradellas, 1998: 217-8). A continuación, planteamos un análisis intradiscursivo de Duel: estudiamos primero el discurso narrativo y después otros discursos culturales que también conforman la estructura del texto.

\section{DUEL: DISCURSO NARRATIVO}

La historia que se cuenta en Duel es muy simple: una fuerza A (camión) se opone a otra fuerza B (coche de David Mann), ambas se enfrentan y B triunfa. El desarrollo temporal y diegético son lineales: la acción comienza al amanecer con las imágenes del coche saliendo del garaje y abandonando la ciudad, y concluye a la puesta de sol. La única elipsis explícita aparece cuando David se queda dormido, pero nada ocurre mientras él duerme y la acción se reanuda en el mismo punto. El resto, son elipsis en movimiento. El escenario: la carretera, el café de Chuck y dos gasolineras; un montaje paralelo, mientras tiene lugar la conversación telefónica con su mujer, nos traslada por breves momentos a su hogar. El esquema narrativo es igualmente sencillo: presentación del protagonista y su conflicto interno, hecho externo que desencadena el enfrentamiento, evolución paralela de los dos conflictos (interno y externo) y desenlace. Los planos del comienzo en cámara subjetiva (durante más de 3 minutos sólo vemos y oímos lo que ve y oye David Mann al volante de su coche) constituyen, además de una primera aproximación al protagonista, una invitación a que el espectador se ponga en su lugar. El conflicto interno se plantea en la primera gasolinera, durante la conversación telefónica. En ella queda muy claro lo que opina su mujer, su insatisfacción es evidente; el papel del hombre parece vacante en la familia (la mención a la madre, castra, aún más, al personaje). David Mann está muy lejos del héroe clásico de la cinematografía norteamericana, que es, fundamentalmente, un hombre de acción. Representa, a lo sumo, un lejano here- 
dero que ha renunciado a los valores individuales y ha depositado su confianza en el sistema, alguien al que resulta muy difícil apartar de las soluciones aprendidas. Enfrentado a una situación límite, cuando las normas del mundo civilizado (su mundo) entran en colisión con otras más arbitrarias y salvajes, él se aferrará siempre a las primeras y sólo al final, movido por la desesperación, tomará la iniciativa y decidirá actuar. De su antagonista no conocemos nada, ni la personalidad ni los motivos.

El hecho que desencadena el conflicto externo es nimio: el coche adelanta en precario al camión (hablo del segundo adelantamiento, realizado en raya continua, cuando el camión deja oír por primera vez la sirena). El café de Chuck marca el punto de inflexión. Es la hora de comer (la información la suministra uno de los monólogos interiores del protagonista), estamos, pues, a mediodía. A partir de este momento la persecución se torna implacable, los ataques del camión (en el paso a nivel, en la segunda gasolinera) persiguen, de forma inequívoca, la aniquilación de su oponente. Paralelamente, el desarrollo del conflicto interno parece marcado por una presencia femenina, anecdótica pero significativa, que juzga, con ojos inquisidores, el comportamiento del protagonista. En la primera gasolinera, una mujer carga su lavadora mientras David habla por teléfono; en el café, la camarera asiste al triste espectáculo de la pelea y posterior expulsión; la segunda gasolinera está atendida por una mujer y durante la persecución que tiene lugar a continuación, la cámara se sitúa, en una toma, detrás de otra mujer que tiende su colada; por último, cuando detiene al coche en que viajan dos ancianos para pedir ayuda, es la mujer la que se muestra más reacia a escucharle. Todo un mundo de mujeres observando a David Mann.

El clímax alcanza su punto culminante en la subida del puerto, cuando ya el duelo ha sido aceptado, y el coche comienza a fallar; enseguida llegaremos al desenlace. Los planos finales, con la puesta de sol enrojeciendo el cielo, y la silueta de David, a contraluz, reflexionando sobre lo sucedido, elevan al protagonista a un plano superior: el del hombre que se ha encontrado a sí mismo.

El relato está construido en torno a dos estructuras narrativas clásicas, que actúan de forma conjunta: el punto de vista y el suspense. Al abordar el problema del punto de vista en el cine, debe tenerse en cuenta que la subjetividad del film no viene marcada solamente por lo que ve el personaje (el espectador sólo ocupará el punto de vista ocular del personaje en contadas ocasiones, cuando la cámara capta su mirada), sino por la forma en que está focalizado el relato, es decir, por la forma en que el narrador suministra 
al espectador lo que sabe el personaje, consiguiendo que ambos den a la información el mismo sentido 4 . Sobre este punto confiesa Hitchcock a Truffaut, a propósito de Rebeca:

[...] la señora Danvers casi no anda, nunca se la veía moverse. Por ejemplo, si entraba en la habitación en que estaba la heroína, la muchacha oía un ruido y la señora Danvers se encontraba allí, siempre, de pie, sin moverse. Era un medio de mostrarlo desde el punto de vista de la heroína: no sabía jamás donde estaba la señora Danvers y de esta manera resultaba más terrorífico; ver andar a la señora Danvers la hubiera humanizado (Truffaut, 1993: 95).

Del mismo modo, si en Duel pudiésemos ver el rostro del conductor del camión, se rompería el artificio sobre el que pivota todo el discurso narrativo. El reto de visualizar el film a través de los ojos del protagonista lleva al realizador a adoptar la estructura informativa: espectador sabe — protagonista sabe - frente a resto de personajes no saben, que genera un sentimiento de complicidad en el espectador, deseoso de participar en diversos momentos de la película (por ejemplo, en el café de Chuck, intentando reconocer las botas entrevistas en la primera gasolinera o cuando corre con David para averiguar la identidad del camionero). Aunque casi siempre la información es compartida en tiempo real, en alguna ocasión la cámara prima a uno de los dos con algunos segundos de ventaja. En la secuencia del autobús escolar, es el espectador el primero en ver al camión (plano general) y, por el contrario, en el último encuentro, cuando el coche frena bruscamente en la curva, el motivo (cómo no, el camión) se desvela al espectador unos momentos después de que lo conozca David Mann.

Los trazos gruesos con que Spielberg subraya el último eslabón de la cadena (resto de personajes no saben) se traducen en el film en un rechazo generalizado hacia el protagonista, que parece trasplantado de otro mundo. Nadie le entiende. Su aspecto pulcro (sólo él lleva traje y corbata) choca con el del resto de los personajes, lo mismo que sus modales afectados. Después de haber escuchado el relato angustiado de David Mann, por ejemplo, el viejo granjero que le atiende al derribar la valla en las proximidades del café de Chuck, comenta, despreocupado y divertido, a un tercero: «Je, je, no pasa nada. Es sólo un poco de tortícolis». Cuando el camarero del café le pregunta por su estado, la burla es evidente. Más tarde, el conductor del autobús es-

${ }^{4}$ En Duel predomina la narración con punto de vista interno o subjetivo, es decir, el enunciador dice o muestra sólo aquello que saben los personajes (en este caso David Mann). En el relato audiovisual no se suele hablar de subjetividad en un sentido absoluto (Conforti, 1987: 56-64). 
colar tampoco le comprende: «Si me preguntaran si hay algún loco por aquí diría que es usted». Los niños se ríen...

En cuanto a la estructura de suspense, mantiene tres líneas de interés: ¿Quién conduce el camión? ¿Por qué algo que empezó siendo un incidente sin importancia se ha convertido en un duelo a muerte? ¿Cuándo se producirá el enfrentamiento definitivo y quién resultará vencedor?

Las dos primeras no se desvelarán en la película, son auténticos macguffins. La última, que presenta el desarrollo clásico de exposición, nudo y desenlace, está muy bien dosificada, con alternancia de puntos fuertes y débiles que contribuyen a mantener la tensión:

- El inicio de la película, con la sucesión de encadenados, incide en el progresivo desarraigo del protagonista de su medio natural (paisaje urbano, arrabales, autopista, carretera secundaria, paisaje desértico...).

- Los primeros rifirrafes con el camión se presentan de forma natural, como incidentes sin importancia.

- Primera gasolinera. Los intentos por conocer la identidad del conductor del camión no pasan de ser simples manifestaciones de curiosidad.

- En los adelantamientos posteriores, las posturas se recrudecen, el acoso es implacable. La intensidad dramática se acentúa en la persecución. El conflicto está ya planteado.

- Café de Chuck. Una primera sensación de alivio y enseguida el desengaño. El aislamiento del protagonista resulta patético. Necesita averiguar quién conduce el camión, pero duda, no se decide, se equivoca, llega tarde... El espectador se siente fuertemente comprometido, no soporta la tensión interior, ;quiere actuar!

- El episodio del autobús escolar, desconcertante, y enseguida el brutal ataque del paso a nivel. Llegada a la segunda gasolinera y nuevo ataque del camión, especialmente demoledor, que destroza la cabina telefónica y las jaulas de reptiles. La agresividad contenida en imágenes anteriores desemboca ahora en una manifestación explícita de destructora violencia.

- Pausa. El protagonista decide abandonar. Se aparta de la carretera y se queda dormido. Elipsis. Retumbar del tren en los raíles. Vuelta a la carretera. 
- De nuevo el camión. Comienza el duelo. La acción llega a su clímax en el puerto.

- El camión se precipita por un barranco. Unas imágenes del ocaso facilitan la recuperación anímica del espectador. Fin.

\section{DUEL: DISCURSO DE LA SOCIEDAD}

Durante las décadas de los 60 y 70, Estados Unidos vive una fuerte convulsión social que aparece simbolizada políticamente en el fracaso de la New Frontier y el escándalo Watergate. Pero este período alberga también el definitivo resquebrajamiento del emblema de toda una nación: el automóvil. Los accidentes de tráfico, la contaminación atmosférica, el declive de la industria, la proliferación de las áreas suburbanas, etc. contribuyen a fraguar la nueva imagen del coche como un elemento perturbador que nos mata, contamina y destruye nuestras ciudades. Ernest B. Furgurson lo resume perfectamente en un artículo de Los Angeles Times (22 de marzo de 1973):

The automobile has metamorphosed, from servant to master. The highway has passed the point of merely linking towns and cities, until now it functions mainly to channel congestion and pollution back and forth from cities to suburbs... To continue to ram roads into our cities without making a major effort to develop parallel systems is to assure our strangulation (Flink, 1976: 194-5).

Duel funciona como una alegoría sobre la situación del automóvil dentro de la sociedad norteamericana, si admitimos las siguientes premisas. (A) David Mann no se enfrenta con otro conductor sino con una máquina, el camión. Mientras este personaje aparece ampliamente caracterizado en la película, del conductor del camión no sabemos nada: apenas hemos visto los extremos de unos pantalones vaqueros y unas botas cuando repostaba gasolina o su brazo por fuera de la ventanilla de la cabina en algunos planos de carretera. Las abundantes secuencias de persecución se resuelven mediante la alternancia de planos del camión y el coche, pero mostrando estos últimos en muchas ocasiones el rostro (humano) de David. (B) El enfrentamiento tiene lugar en la carretera, que deja de funcionar como espacio centrífugo y se convierte en una especie de ring. No se trata de autopistas, sino de carreteras secundarias de la América profunda muy poco transitadas. (C) El camión es un personaje monstruoso que puede contemplarse como metáfora de todos los aspectos negativos asociados al automóvil. Tiene ojos desafiantes (recuérdese su presencia con los faros encendidos en la boca del túnel) y emite escalo- 
friantes aullidos ${ }^{5}$. La planificación empleada para mostrar su destrucción y el sonido lastimero y agónico que la acompaña subrayan esta impresión ${ }^{6}$. En la parte posterior de su cisterna el rótulo de FLAMMABLE parece advertir de su carácter irascible. (D) El Plymouth Valiant de David Mann es la antítesis del camión: pequeño, limpio, humanizado..., pero no representa valores positivos: involucra a David en el duelo a muerte, mantiene encerrada toda su incertidumbre y finalmente debe ser entregado como ofrenda a la bestia mecanizada: Mann sólo consigue vencerla cuando lanza su Plymouth contra el monstruoso Peterbilt. (E) Entre David y su oponente mecánico se establece una intensa lucha por la dominación. La máquina se rebela para ejercer como dominadora (master) del hombre (servant). La desigualdad de tamaño existente entre el camión y David (con o sin su coche) es hábilmente explotada en Duel: los planos del camión se toman de modo que no quepa en el encuadre, en ligero contrapicado, presentando preferentemente la parte baja de la cabina con el frontal del radiador y las protecciones delanteras, que cuando empujan al coche parecen morderlo; en los planos de situación, cuando los dos vehículos aparecen juntos, las proporciones mastodónticas del camión minimizan las de su oponente.

Esta lectura sociológica se puede aplicar a otros filmes posteriores más o menos derivados de Duel, como The Car (Asesino invisible, Elliot Silverstein, 1977) o Christine, adaptación de la novela homónima de Stephen King, realizada por John Carpenter en 1983.

\section{DUEL: DISCURSO DEL CINE}

Una característica fundamental de la cultura de masas es la proliferación en los textos audiovisuales de citas y referencias de todo tipo (SánchezBiosca, 1995: 17-31). La película de Spielberg puede ser un buen exponente de ello.

\footnotetext{
${ }^{5}$ Los sonidos que emite su sirena tienen un amplio registro: unas veces son cortos y secos, como una advertencia, y otras veces prolongados y agudos, como un grito. En la primera gasolinera incluso se emplean para solicitar el servicio, en sustitución del lenguaje hablado.

6 Sobre este tema manifestaba Spielberg:

El protagonista era el camión. Lo elegimos como si se tratara de un actor. Cuando encontramos uno que podía tener una cierta cara humana, lo pintamos de óxido, le echamos aceite, pusimos saltamontes muertos en su parabrisas, le añadimos dos trozos de raíl como parachoques y a los lados pusimos una especie de orejas. Lo que más trabajo nos costó es que echara humo constantemente. Yo quería que no dejara de hacerlo en ningún plano de la película. Tenía que tener vida propia (Galán, 1983: 50).
} 
En primer lugar, podemos encontrar en Duel diversas afinidades con el western ${ }^{7}$. Su título recuerda el de algunas famosas películas como Duel in the Sun (Duelo al sol, 1946) de King Vidor, The Duel at Silver Creek (1952), de Don Siegel o Duel at Diablo (Duelo en Diablo, 1966), de Ralph Nelson. Utiliza elementos temáticos propios del género: la persecución, la emboscada, el enfrentamiento. Al igual que los escenarios: si en el western la calle es el elemento dinámico y dramático por excelencia, el espacio donde tiene lugar el duelo, aquí lo es la carretera, en ella transcurre casi toda la acción, incluido parte del enfrentamiento final, tanto tiempo aplazado y que se produce al ponerse el sol, como en Stagecoach (La diligencia, 1939), de John Ford, Shane (Raíces profundas, 1953), de George Stevens, o Decision at Sundown (1957), de Budd Boetticher; otros elementos comunes serían el paisaje desértico y el saloon (el café de Chuck), lugar de encuentro donde se toman decisiones importantes. El cine del Oeste es un género tradicionalmente escéptico frente a las ventajas que trae consigo la civilización. La aparición del coche en algunos westerns crepusculares tiene siempre connotaciones negativas, como en The Ballad of Cable Hogue (La balada de Cable Hogue, 1970), de Sam Peckinpah, donde acaba con el viejo pistolero que no puede detener su avance. Esta reflexión adquiere un significado especial en Duel, si consideramos el enfrentamiento entre David y el camión desde la óptica de la lucha del hombre contra la máquina. El cementerio de automóviles que aparece en distintos planos mientras David duerme, anticipa que, al final, las dos máquinas, el coche y el camión, serán destruidas. Es importante recordar, al respecto, el monólogo en el baño del café de Chuck: «... te sientes tan indefenso como si el mundo se hubiera convertido en una selva...»

La persecución y el acoso del camión están sazonados por la intriga -David Mann no sabe quién lo persigue, sólo sabe que lo persiguen-, lo que conecta la película de Spielberg con el cine de suspense, especialmente el de Alfred Hitchcock. Además, el protagonista es un hombre corriente enfrentado a una situación límite, personaje que el director británico utilizó en muchas ocasiones. Es posible apreciar en Duel referencias específicas a algunas películas de este director. El planteamiento aparentemente absurdo, el inexplicable acoso del camión, remite a The Birds (Los pájaros, 1963) ${ }^{8}$ (Sinyard, 1987: 14; Kaufman, 1983: 19). El ataque en la segunda gasolinera, cuando David se en-

7 «[...] le choix des extérieurs, le caractère désertique des contrées traversées permet une "lecture" westernienne sur le thème de la poursuite, et de l'embuscade, cependant qu'une des premières scènes du film suggère une analogie entre le camion poursuivant et un agent "polluant"» (Eyquem, 1973: 82).

${ }^{8}$ Es interesante reseñar la respuesta que dio Hitchcock a Truffaut cuando éste, a propósito de Los pájaros, le comentaba la incredulidad del público: 
cuentra en la cabina intentando hablar por teléfono, recuerda al de la avioneta fumigadora en North by Northwest (Con la muerte en los talones, 1959), en un paisaje igualmente desértico, cuando Roger Thornill (Cary Grant) espera el autobús. Las notas musicales que subrayan el acercamiento del camión al coche en la última parte de Duel, evocan la banda sonora de Bernard Hermann para Psycho (Psicosis, 1961) y traen a la memoria la figura de Norman Bates (Anthony Perkins) al acecho en la ducha.

\section{DUEL: DISCURSO DEL ARTE}

Es indudable que existen bastantes analogías entre Duel y la estética hiperrealista (especialmente la pintura), tan en boga en la sociedad norteamericana de finales de los sesenta y principios de los setenta.

La imaginería visual de Duel (coches, gasolineras, señales de tráfico, carteles, hombres y mujeres vulgares...) es la que, preferentemente, cultivan estos artistas. Todos ellos acostumbran a utilizar multitud de fotografías, valiéndose de sus encuadres y de otros efectos puramente fotográficos para realizar sus composiciones. Así, podremos observar en ellas angulaciones extrañas, la no-distancia de la técnica instantánea fotográfica (Chuck Close) y puntos de vista fragmentarios de los objetos que representan (las motos de David Parrish o los coches de John Salt, por ejemplo).

La planificación de Duel utiliza una técnica compositiva similar: primeros planos de David Mann, puntos de vista fragmentarios de los vehículos e incluso los espejos retrovisores (estas pinturas reproducen también minuciosamente cualquier efecto de luz o reflejo captado por la cámara fotográfica).

Hay que recordar, por otro lado, que Duel fue realizada, en primera instancia, para la televisión (en 1960 el 90\% de los hogares norteamericanos disponían ya de televisión), medio que nos traslada una nueva dimensión de la realidad. Paul Sager escribía allá por 1972: «La vida es televisión y la televisión es la vida: he aquí la fórmula calderoniana de nuestra época» (Sager, 1986: 13). Esta categoría inicial de telefilm (las películas para la televisión

Así es; van al cine, se sientan y dicen: «Vamos a ver». Después sienten deseos de anticiparse: «Adivino lo que va a suceder». Y yo me veo obligado a recoger su desafío: «iAh, sí! ¿Usted cree? ¡Muy bien! ¡Veremos!’ En The Birds actué siempre de tal manera que el público nunca pueda adivinar cuál será la escena siguiente (Truffaut, 1993: 234).

Pueden encontrarse más afinidades entre The Birds y Duel: la minuciosa elaboración del storyboard, el preciso montaje del sonido y el excesivo número de planos. 
están frecuentemente dedicadas a dramatizar hechos de la vida real o temas cercanos a los reportajes de actualidad) significa que Duel nació supeditado al principio del high concept, o idea básica sobre la cual gira todo el desarrollo, que se explota al máximo durante su duración (los telefilms, a diferencia de las series, no disponen de más tiempo para ello) y que ya se expresa claramente en el título (Villagrasa Sebastián, 1998: 219-20, 244).

La manipulación o reelaboración de la realidad que nos ofrecen tanto la televisión como Duel presenta bastantes coincidencias con el procedimiento seguido por los artífices del Hiperrealismo, que el escultor Duane Hanson explica de la siguiente forma:

Una pregunta difícil es la relación que existe entre la objetividad de los cuerpos verdaderos y la de mis esculturas. La corporeidad de las personas concretas sirve de prototipo a las esculturas; es el trabajo más original o conceptual, que nunca se copia íntegramente (además de inoportuno sería imposible), sino que se transforma, más bien, en una versión sintética del original. La obra concreta se perfila como manifestación duradera del original, se solidifica y se acentúa. Si se trata, por ejemplo, de un tema crítico-social, la metodología técnica para conseguir ese objetivo puede consistir en manipular el tamaño o la figura corporal, la postura, la indumentaria, el tratamiento del detalle, la pintura independiente de los sectores..., hasta alcanzar el objetivo con todas estas condiciones. Realidad e ilusión son completamente diferentes, pero se las obliga a parecer muy semejantes cuando se manejan todos esos detalles de forma que aludan a la totalidad. De este modo, el observador descubre el engaño, pero se pregunta cómo se le engañó. Si logra responder a esto, se dará cuenta que el artista ha resuelto el problema desde el principio con la elección del tema, la composición, la indumentaria y la observación del detalle, porque se preocupa más por esas relaciones sutiles (Sager, 1986: 207).

\section{DUEL: DISCURSO DE LA LITERATURA}

Duel es una película terriblemente realista y, en ella, está presente en todo momento lo inverosímil. ¿Hay en esto una contradicción? Veamos la opinión de Juan C. Rentero:

[...] Duel resulta sin remedio un film absolutamente fantástico y, por supuesto, fuera de toda realidad concretizada, ya que delata una injerencia en terrenos sublimados que a su vez sobrepasan todo tipo de lógica. Esto es lo que me lleva a una auténtica sorpresa, al comprobar que la mayoría de las 
críticas de Duel se detienen a examinar el carácter realista de la película. Creo que es una flagrante contradicción, la ignorancia a omitir todo el sentido externo de la cinta, en principio, así como violar uno de los más importantes ejes donde descansa el film: el fantástico, antes citado, bien entendido desde una óptica de puro juego onírico. [...] Duel puede ser tanto una pesadilla como un sueño — si no ambas cosas a la vez-, pero jamás una realidad, y de hecho me temo que Spielberg la realizó con esta misma intencionalidad (Rentero, 1978: 48).

La convivencia del realismo con lo fantástico no debe verse, pues, como una contradicción, ya que, por el contrario, la hiperrealidad es un elemento fundamental del relato fantástico, pues sin ella no podría producirse, de manera efectiva, la ruptura que caracteriza al género 9 .

Todorov observa que, en el mundo que conocemos, sin diablos, vampiros o hadas, ante un acontecimiento en apariencia inexplicable, sólo podemos escoger entre dos opciones: o bien lo consideramos un producto de nuestra imaginación o, por el contrario, admitimos que realmente ha ocurrido. Pues, bien, lo fantástico ocupa exactamente el tiempo que dura la incertidumbre y termina cuando realizamos la elección (Todorov, 1974; Palacios Bernal, 1986: 26-27).

Duel representa, por tanto, un ejemplo de lo fantástico en su tradición más pura, la literaria ${ }^{10}$. Que esto sea así no significa que concedamos a Richard Matheson más mérito del que le corresponde como autor del guión y del relato inicial ${ }^{11}$. Por muy sugestivas que resulten sus palabras, para que un guión funcione es imprescindible una buena puesta en escena, y este reconocimiento no debe negársele a Spielberg. Como bien ha dicho Desrosiers:

${ }^{9}$ Ferreras (1995: 20-1) la considera entre los elementos característicos del género:

(1) [...] Elemento sobrenatural inédito: toda narración debe presentar uno o varios elementos que no sigan las leyes naturales [...] (2) Universo identificable o «hiperrealidad» [...] Cabe aquí hablar de un realismo llevado al extremo, que parece representar un universo tan aburrido que no merece ni siquiera que se mencione. (3) Ruptura radical entre el protagonista y el universo: la narración fantástica tiende a oponer de manera constante al protagonista, víctima del elemento fantástico, con sus estructuras sociales, representadas por su familia, sus vecinos o sus conciudadanos.

${ }^{10} \mathrm{El}$ canon del género se estableció, sin duda, en la literatura y el cine no siempre lo ha seguido con tanta fidelidad. No debemos olvidar que Matheson, autor del guión, es un cultivador del género reconocido en los Estados Unidos y que ha adaptado para el cine numerosas novelas y relatos, tanto suyos como de Edgar Allan Poe, entre otros.

${ }^{11}$ Latorre (1983: 31) escribe acerca de Duel: «una interesante película que debe su prestigio cinéfilo más a la brillantez de su planteamiento literario que a la inteligencia de su puesta en escena». Reaparece esta opinión en Latorre (1990: 397). 
«le fantastique est une atmosphère que l'écrivain crée par son imagination et avec ses rêves» (Palacios Bernal, 1986: 25).

En nuestra opinión, Duel es un buen ejemplo de lo fantástico moderno, a medio camino entre la concepción más clásica (a la manera de Hoffman, Poe o Maupassant) y los intentos más contemporáneos de ruptura, como los de J. G. Ballard. Respecto a lo primero, debemos recordar la transformación experimentada por el género a lo largo del siglo XIX, cuando paulatinamente se van abandonando las manifestaciones exteriores de lo fantástico, las intervenciones de lo sobrenatural en la realidad, y se va incidiendo más en la experiencia vivida, en el análisis de las sensaciones. Como indica Maupassant, el progreso tecnológico del siglo XIX hace que el hombre cambie su percepción de lo sobrenatural para siempre. Ya no puede creer en leyendas antiguas y ello obliga al autor de relatos fantásticos a mostrar una mayor sutileza, a utilizar otros recursos para conseguir en el lector ese escalofrío de inquietud, todavía posible porque, en suma, «sólo se tiene miedo de lo que no se entiende $»^{12}$. Este aspecto resulta fundamental en Duel, pues, como hemos visto, todo en la película (entorno y procedimientos narrativos) contribuye a recrear en la pantalla el estado anímico del protagonista ${ }^{13}$.

J. G. Ballard considera, casi 100 años después de Maupassant, que la influencia de la tecnología puede llegar a provocar cambios terribles en la vida del hombre. En su novela Crash, los accidentes de tráfico y sus secuelas se presentan como causa de excitación sexual. El propio autor explica en el prólogo de su novela:

En el pasado dábamos siempre por supuesto que el mundo exterior era la realidad, aunque confusa e incierta, y que el mundo interior de la mente, con sus sueños, esperanzas, ambiciones, constituía el dominio de la fantasía y la imaginación. Al parecer esos roles se han invertido. El método más prudente y eficaz para afrontar el mundo que nos rodea es considerarlo completamente ficticio... y recíprocamente, el pequeño nodo de realidad que nos han dejado está dentro de nuestras cabezas. La distinción clásica de Freud entre el contenido latente y el contenido manifiesto de los sueños, entre lo aparente y lo real, hay que aplicarla hoy al mundo externo de la llamada realidad (Ballard, 1996: 12$)^{14}$.

\footnotetext{
12 Estas experiencias del escritor francés aparecieron por primera vez en Le Gaulois, el 7 de octubre de 1883, según Palacios Bernal (1986: 19-21).

${ }_{13}$ Equivalente a la primera persona gramatical que suelen utilizar estos autores en sus relatos. Como ya se ha dicho, en el cine resulta poco efectivo contar en primera persona (cámara subjetiva) todo el relato.

${ }^{14}$ La obra es de 1973 y el prólogo que la acompaña apareció por primera vez en la edición francesa Calmann-Lévy de 1974.
} 


\section{REFERENCIAS BIBLIOGRÁFICAS}

\section{a) Libros}

BALlard, J. G. (1996). Crash. Barcelona: Minotauro.

BAXTER, J. (1998). Steven Spielberg. Biografía no autorizada. Madrid: $\mathrm{T} \& \mathrm{~B} / \mathrm{JC}$.

FERRERAS, D. F. (1995). Lo fantástico en la literatura y el cine. De Edgar A. Poe a Freddy Krueger. Madrid: Vosa.

FuINK, J. J. (1976). The Car Culture. Cambridge: The Massachusetts Institute of Tecnology Press.

KAUFMAN, D. (1983). Steven Spielberg. Madrid: JC.

LATORRe, J. M. (1990). El cine fantástico. Barcelona: Dirigido por...

MARCheSe, A. y ForRadellas, J. (1998). Diccionario de retórica, crítica y terminología literaria. Barcelona: Ariel.

Palacios Bernal, C. (1986). Los cuentos fantásticos de Maupassant. Murcia: Universidad de Murcia.

SAger, P. (1986). Nuevas formas de realismo. Madrid: Alianza.

SÁNCHEZ-BiosCA, V. (1995). Una cultura de la fragmentación: pastiche, relato y cuerpo en el cine y la televisión. Valencia: Filmoteca de la Generalitat Valenciana.

SinYARD, N. (1987). The Films of Steven Spielberg. London: Hamlyn.

TODOROv, T. (1974). Introducción a la literatura fantástica. Buenos Aires: Tiempo Contemporáneo.

Truffaut, F. (1993). El cine según Alfred Hitchcock. Barcelona: RBA.

VillagRASA Sebastián, J. P. (1998). La producción de ficción narrativa en la televisión norteamericana (Tesis doctoral). Bellaterra: Universitat Autónoma de Barcelona.

\section{b) Volúmenes colectivos}

GonZÁlez ReQuenA, J. (1988). «Del lado de la fotografía: una historia del cine en los márgenes del sistema de representación clásico». En Los 
años que conmovieron al cinema. Las rupturas del 68, J. Pérez Perucha (coord.), 18-30. Valencia: Filmoteca de la Generalitat Valenciana.

\section{c) Artículos}

CONFORTI, A. (1987). «La soggettività nel cinema: Duel di Steven Spielberg». Cineforum 264, 56-64.

Eyquem, O. (1973). «Duel». Positif 150, 81-82.

Galán, D. (1983). «El diablo sobre ruedas. El primer Spielberg». El País, 19 de febrero, 50.

Latorre, J. M. (1983). «Un problema de duración». Dirigido por... 101, 31.

Rentero, J. C. (1978). «Directores americanos de los 70. Steven Spielberg». Dirigido por... 50, 46-49. 